Egyptian

Orthodontic Journal

\title{
SCANNING ELECTRON MICROSCOPIC STUDY OF ROOT RESORPTION AND REPAIR IN RESPONSE TO LOW MAGNITUDES OF FORCE
}

\author{
Dr. Safaa A. Ghobashy* \\ Dr. Suzi Sheneshan**
}

ABSTRACT

The purpose of the present study was to investigate the presence, location and severity of root resorption after orthodontic buccal tipping movement using two magnitudes of force and register root repair following two different periods of retention. Fixed orthodontic appliances were inserted to the first premolars of twenty four patients having maxillary crowding and seeking orthodontic treatment.

In each patient, force of $20 \mathrm{~g}$ was applied to the right side and force of 50g.was applied to the left side. Active tooth movement lasted for 4weeks and followed by retention periods 4 QL 8 weeks for each magnitude of force. All the specimens were examined with scanning electron microscopy. Three distinct types of resorption defects were detected: small isolated lacunae, wide shallow resorption 6ays, and deep lacunae. The number of each type of resroption defect and the distribution over the length of the roots varied with the magnitude of force. The pattern of repair was partial, functional or anatomical depending on the type of resorption defect and the retention period.

In conclusion, the force of $20 \mathrm{~g}$ resulted in few and shallow resorption lacunae mainly at the cervical and middle thirds of the

\footnotetext{
* Assistant Professor. of Orthodontics. Tanta University

** Assistant Professor of Oral histology. Ain Shams Univeristy.
} 
Egyptian

Orthodontic Journal

buccal surface, while the force $50 \mathrm{~g}$ resulted in deeper lacunae that were detected on the buccal surface with the middle and apical thirds of the lingual surface. Repair process started during active tooth movement and the healing potential increased greatly in the retention periods.

\section{INTRODUCTION}

Root resorption is an unavoidable pathologic consequence of orthodontic tooth movement that results in permanent loss of tooth structure from the root surface $^{(1,2)}$. The identification of factors that predispose a patient to root resorption has been the focus of numerous studies ${ }^{(3-7)}$. These factors include age, sex, systemic condition, type of malocclusion, tooth structure and treatment factors such as type of appliance, duration of treatment, type of tooth movement and orthodontic force magnitude.

In order to move a tooth orthodontically, a force with an appropriate magnitude is needed to initiate proper remodeling of tooth- supporting tissues. Ideal tooth movement should occur with the blood capillary pressure of 7 to $26 \mathrm{~g} / \mathrm{cm}^{2}{ }^{(8)}$. Too low and inconsistent forces will not start tissue reactions and will, therefore, not be able to move the tooth. While too high forces are believed to cause excessive root resorption ${ }^{(9,10)}$.

Force magnitude greater than $100 \mathrm{~g}$ results in a lag phase of approximately 21 days before tooth movement occurs ${ }^{(8,10)}$. Owman- Moll et $\mathrm{al}^{(11)}$ found no difference in tipping movements of human premolars with forces of $50 \mathrm{cN}$ and $100 \mathrm{cN}$. Iwasaki et $\mathrm{al}^{(12)}$ found that continuous forces of $18 \mathrm{~g}$ and $60 \mathrm{~g}$ can be used to retract maxillary canines with effective tooth movement and average velocities 0.87 and $1.27 \mathrm{~mm} / \mathrm{month}$ respectively, without a lag phase and with minimal unwanted linear or angular tooth movement. They concluded that higher forces do not necessarily lead to faster tooth movements. The extent of root resorption has never been identified and correlated to the amount of forces used.

Few investigations of the reparative potential of root resorption have been published ${ }^{(13-18)}$. In orthodontic patients, the healing process of a resorption cavity is believed to start when orthodontic force is discontinued or reduced to below a certain level ${ }^{(19,20)}$. On the other hand, it may be seen simultaneously with the resorption process ${ }^{(15,21-23)}$. However, despite years of dedicated research, little light has been shed on the relation between low force magnitudes and the topography of root resorption and repair. 
Egyptian

Orthodontic Journal

Consequently the aim of the present work was to investigate the effects of two magnitudes of light force $(20 \& 50 \mathrm{~g}$.) on root resorption, and healing following the cessation of the forces, using scanning electron microscope.

\section{Materials and Methods:}

\section{Experimental design and orthodontic appliance:}

Forty eight maxillary first premolars from 24 adolescent, aged 13-16 years were used in this study. The patients were selected from Orthodontic clinic, Faculty of Dentistry, Tanta University, they had bilateral maxillary crowding or maxillary protrusion. Orthodontic treatment for these patients would include bilateral first premolar extractions, and the extractions postponed for the purpose of this study. The subjects were selected according to strict criteria, which included normal growth and development of the dentition, no medical history that would adversely affect the development of the teeth, and no history of bruxism. The selected premolars must have undergone complete apexogenesis, which was confirmed radiographically with a periapical radiograph. The selected teeth must had no previous trauma, caries, periodontal disease, dental or orthodontic treatment. All patients were fully informed about the procedures, and their parents' written consent was obtained.

For each patient a fixed orthodontic appliance was inserted at the start of the experiment (Fig.1. A,B). It consisted of molar bands on the maxillary first molars, supplied with buccal tubes. A lingual arch with an anterior acrylic bite block was soldered to the molar bands to minimize occlusal forces on the tested teeth.

The first premolar was moved buccally with a sectional arch, 0.016" st.st. with helix mesial to the buccal tube of the upper first molar, ligated to a bonded 0.018 " twin bracket attached to the buccal surface of the test tooth.

The arch wire was activated by bending the wire mesial to the molar tube to provide a horizontal and buccally directed force of $20 \mathrm{~g}$ at the right side and $50 \mathrm{~g}$ at the left side of the experimental teeth. The force was measured with a strain gauge (Haldex, Halmstad, Sweden) calibrated to the nearest $1 \mathrm{cN} \simeq 1 \mathrm{~g}$. The strain gauge was held perpendicular to the sectional arch just mesial to the bracket to standardize the measuring procedure. The sectional arch was adjusted until two consecutive measurements showed the same value after which it was ligated to the bracket.

After 4 weeks of force application the right and left maxillary first premolars were extracted from eight patients, then passive sectional arch wires 
(st.st. 017" X 022") were applied for retention in the remaining 16 patients. The wires were adjusted to fit the bracket on the orthodontically moved teeth and left for 4 weeks in 8 patients and for 8 weeks in 8 patients. Accordingly the collected teeth were divided into 6 groups of 8 teeth each:

Group I: active movement with $20 \mathrm{~g}$ force for 4 weeks.

Group II: active movement with $50 \mathrm{~g}$ force for 4 weeks.

Group III: retention period for 4 weeks after movement with $20 \mathrm{~g}$ force.

Group IV: retention period for 4 weeks after movement with $50 \mathrm{~g}$ force.

GroupV: retention period for 8 weeks after movement with $20 \mathrm{~g}$ force.

GroupVI: retention period for 8 weeks after movement with $50 \mathrm{~g}$ force.
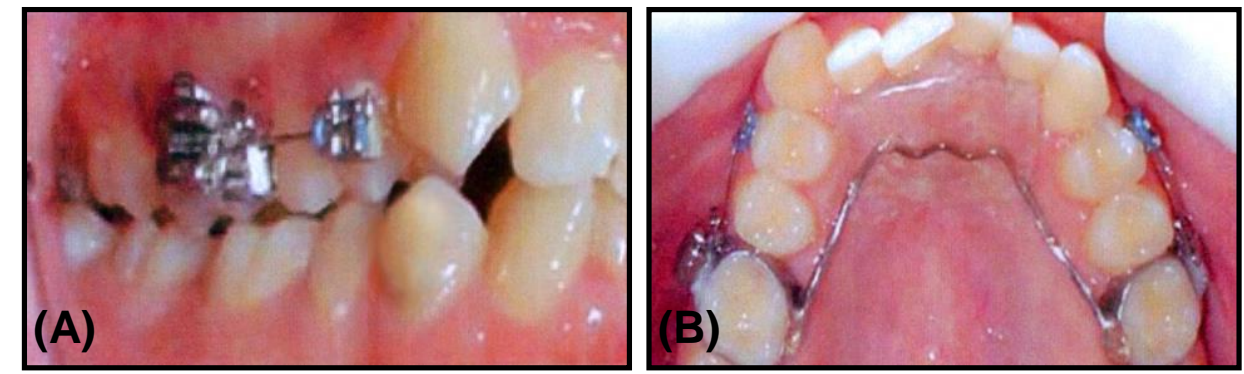

Fig.1: Intra oral photos with active appliance in place. A, sectional arch used to apply buccally directed force on the upper first premolar. Note premolars disengaged from occlusal contact. B, occlusal view of the appliance.

\section{Preparation for scanning electron microscopy:}

At the end of the experimental period, the teeth were extracted, cleaned and fixed in a solution containing 2.5\% Formaldehyde freshly prepared from Para-formaldehyde. The roots were separated from the crowns with diamond discs under water spray just occlusal to the cemento- enamel junction.

The roots of group I and II were treated with $2 \%$ sodium hypochlorite for 30 minutes to remove the non mineralized organic components. After that all roots were washed with distilled water, dehydrated in grades of ethanol baths and dried in air. The specimens were mounted on aluminum stubs and coated with gold in a high vacuum evaporator to thickness of $10 \mathrm{~nm}$. The buccal and 
lingual surfaces were examined with SEM at $25 \mathrm{KV}$ at the Faculty of Science, Alexandria University.

\section{Registration of root resorption and repair:}

All the resorption areas detected on the buccal and lingual surfaces of the samples were digitally obtained, the number of each of three morphologically distinct types of lacunae (small isolated, superficial bays and deep lacunae) ${ }^{(24)}$ was registered.

By using the stereo imaging, the buccal and lingual surfaces were divided into three equal regions along the long axis of the root apex (Fig.2). These regions were labeled 11, 12, 13 for buccal cervical, middle and apical zones and 21, 22, 23 for lingual cervical, middle and apical zones respectively. The regions 11 and 23 were considered compression areas and regions 13 and 21 tension areas, while regions 12 and 22 had undergone a combination of compression and tension.

Repair was registered whenever lacunae revealed newly formed cementum, and three distinct registrations were made; partial repair where part of the resorped cavity was covered with new cementum, functional repair where the total surface of the resorption cavity was covered with cementum without reestablishment of the original root contour, anatomical repair, where the reparative cementum was laid down to such extent that the original root contour was reestablished ${ }^{(15)}$.

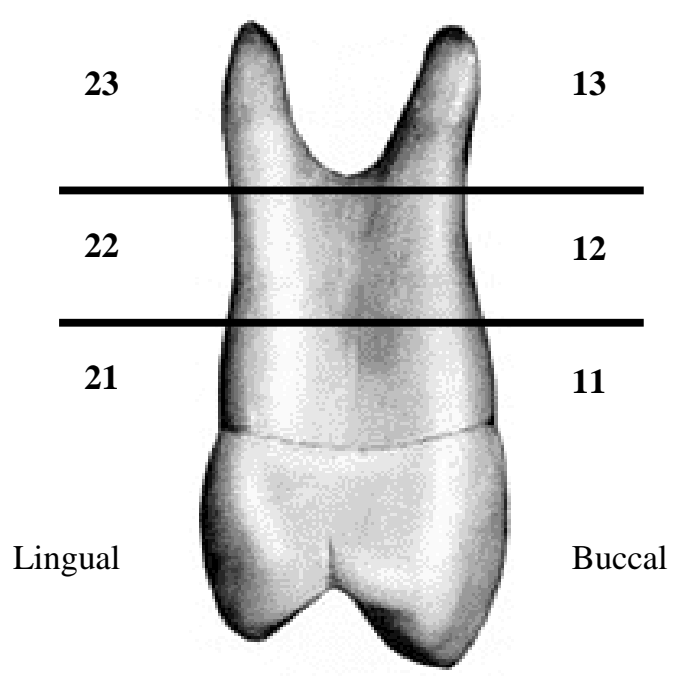

Fig.2: Diagrammatic representation of demarcation of regions in sample 
Egyptian

Orthodontic Journal

\section{RESULTS}

\section{Root resorption findings:}

Examination of the root surface registered resorptive areas on the cementum of all the teeth subjected to active tooth movement with great variation concerning both occurrence and severity (Fig. $3 \& 4$ ).

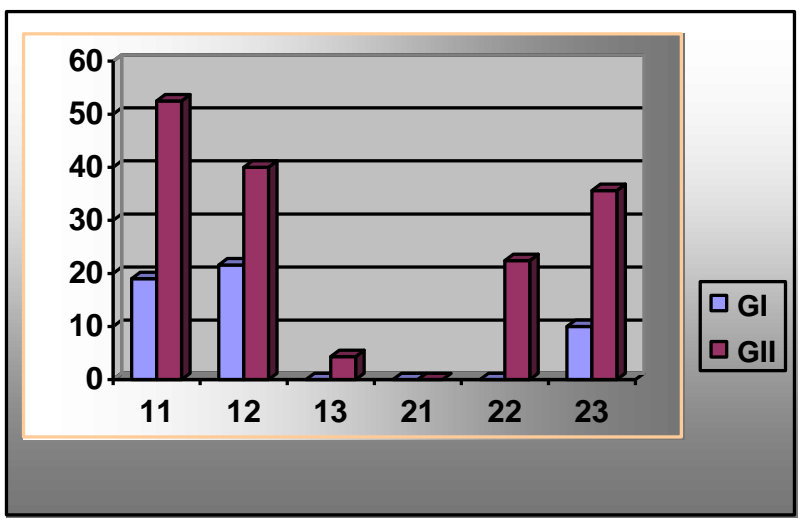

Fig.3: Histogram representing the mean of resorption areas per different root regions.

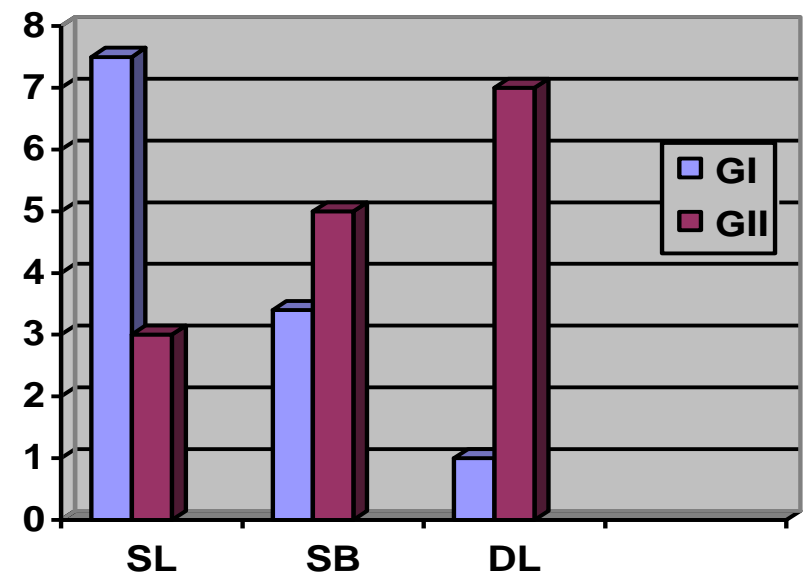

Fig.4: Histogram representing the different types of resorption areas SL: small isolated lacuna, SB: shallow resorption bay, DL: deep lacuna 
Egyptian

Orthodontic Journal

\section{Group I: teeth subjected to $20 \mathrm{~g}$ of force:}

The amount of root resorption nevertheless the type of the lacunae was significant at region $11 \& 12$ compared to other regions. The least amount of resorption lacunae was detected at region 23 . Regions $13,21 \& 22$ never show resorption lacunae. This group showed the highest incidence of small isolated lacunae along the root but rarely on region 13, while wide shallow resorption bays involving only the cementum were less detected at the specified regions (Fig 5\&6).

\section{Group II: teeth subjected to $50 \mathrm{~g}$ of force}

Region 11 had the most significant amount of resorption, while regions $12 \& 23$ were almost equal. Regions 13 showed the least frequency, while region 21 never show resorption lacunae. Although the apical third possessed many resorption lacunae, the apical contour was not affected. Deep lacunae showed high incidence in comparison to shallow bays and small lacunae, they commonly possessed undermined edges. Also deep resorption lacunae with or without dentin involvement were invariably located in a field of already exciting shallow resorption bays (Fig.7). Wide and deep resorption lacunae penetrating into dentin were noticed at the buccal surface, the lacuna possessed areas of earlier repair (Fig.8).
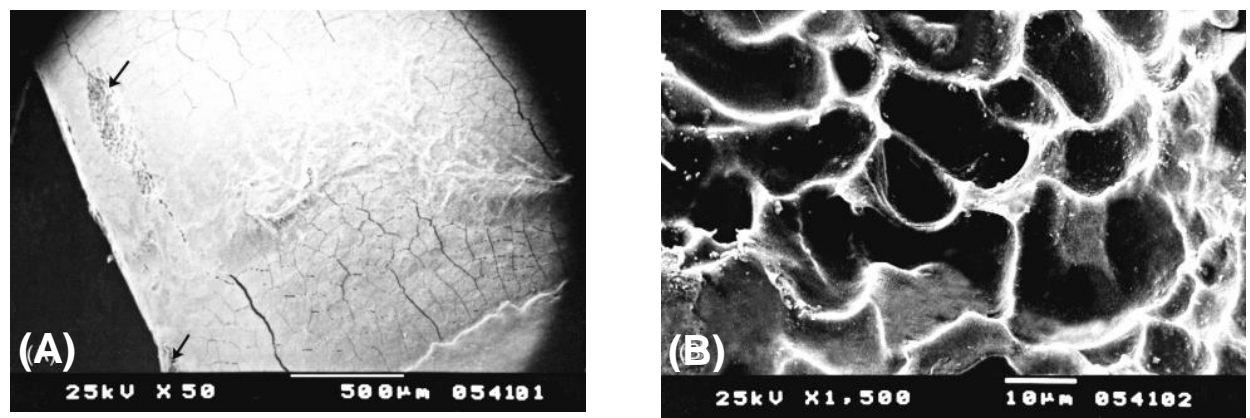

Fig.5: SEM of group I root showing: (A) wide shallow resorption bays at the cervical and middle thirds (arrows), (B) high magnification of multiple smooth resorption lacunae indicating active resorption. 

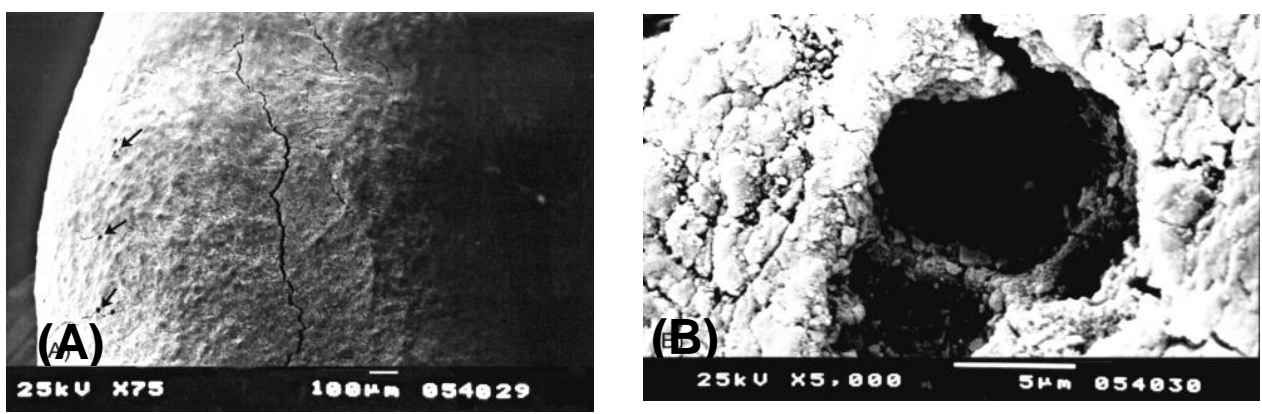

Fig.6: SEM of group I showing: (A) small isolated lacunae (arrows) in the middle third of the root, (B) the lacunae are not deep with no detectable dentin involvement.
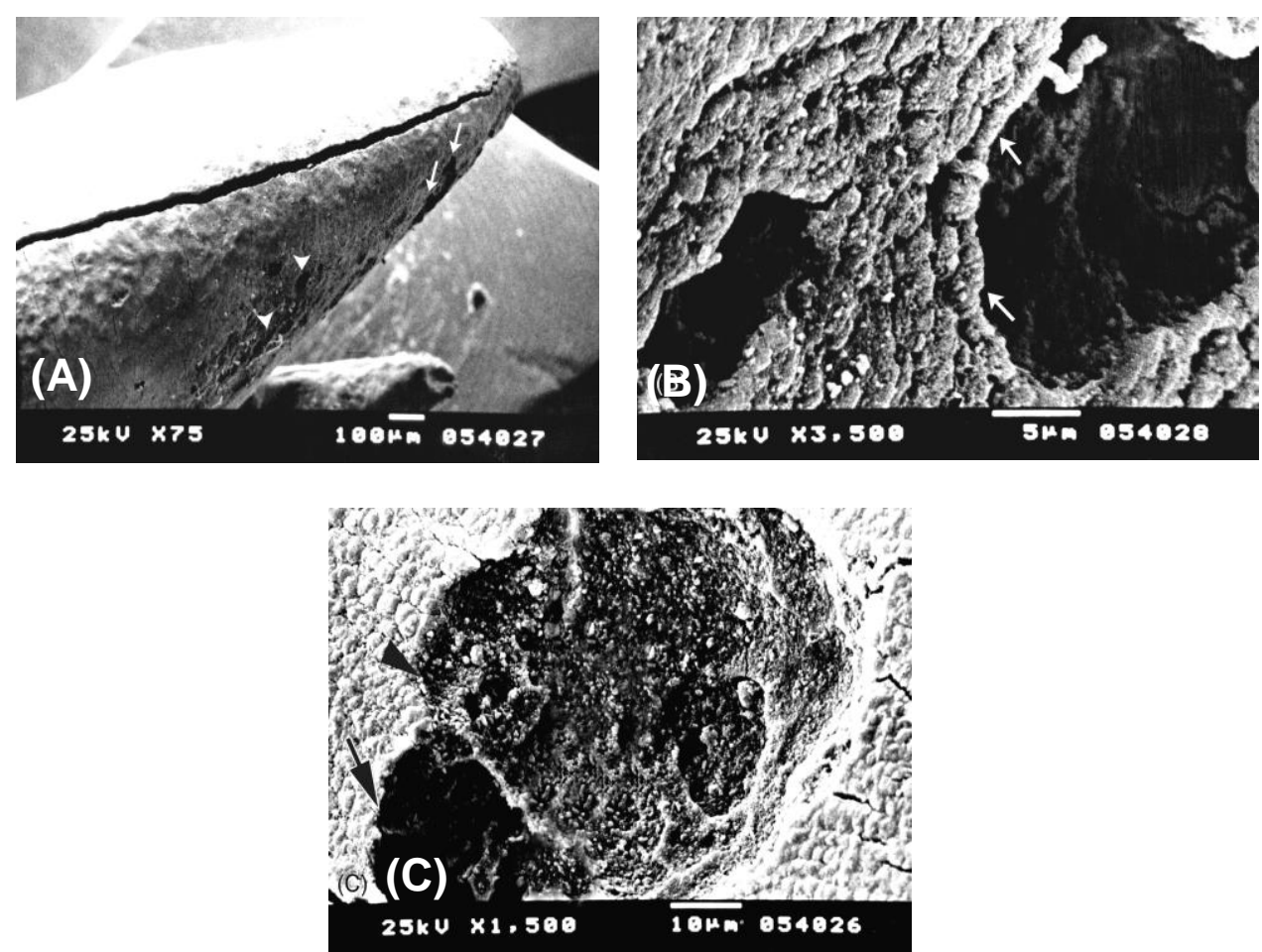

Fig. 5: SEM of group II root showing: (A) many deep lacunae (arrows) as well as wide resorption areas (arrow heads) with preserved apical contour. (B) deep resorption lacuna with undermined edges, (C) Deep resorption lacuna (arrow) in continuity with shallow resorption bay possessing partial repair (arrow heads). 

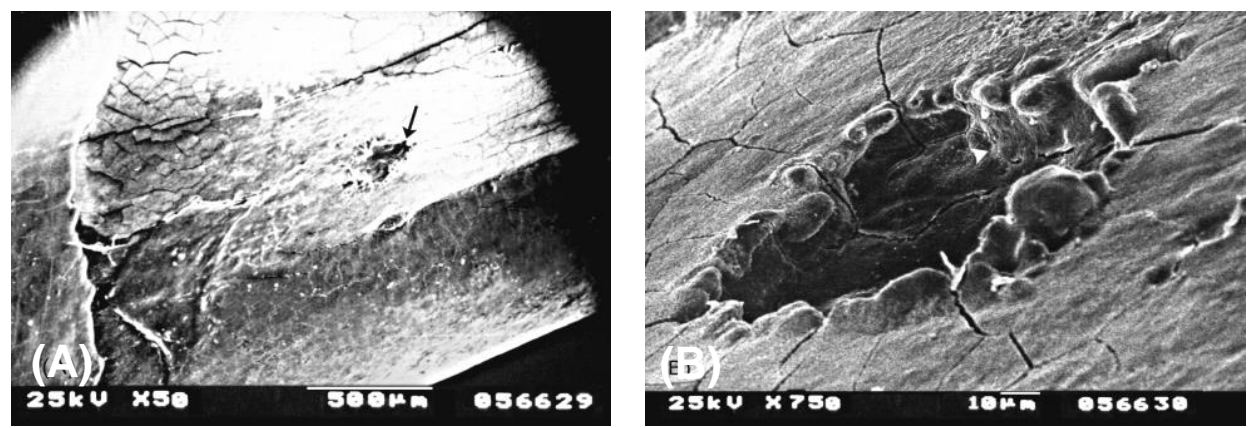

Fig. 8: (A) Deep resorption area (arrow) at the middle third of group II root, (B) area of earlier repair (arrow head) at the floor of the lacunae.

\section{Repair findings:}

Examination of roots after retention periods revealed the commence of reparative process in all teeth. The pattern of healing and cement deposition either partial, functional or anatomical depended on the type of resorption lacunae and the retention period.

Group III \& IV: retention period for 4 weeks after active movement with 20 or $50 \mathrm{~g}$ :

The roots showed many areas of partial and functional repair. This was evidenced by the presence of thin layer of cementum irregularly distributed at the floor of shallow resorption bay (Fig.9). Deep isolated lacunae showed cementum repair at the periphery with or without fiber insertion (Fig. 10).

Group V\& VI: retention period for 8 weeks after active movement with 20 or $50 \mathrm{~g}$ :

Most of the resorption areas showed anatomical repair almost restoring the outline of the root. The newly formed cementum showed many intrinsic fiber bundles of various diameters arranged parallel to root surface (Fig.11). Deep lacunae with dentin involvement possessed incomplete healing. 

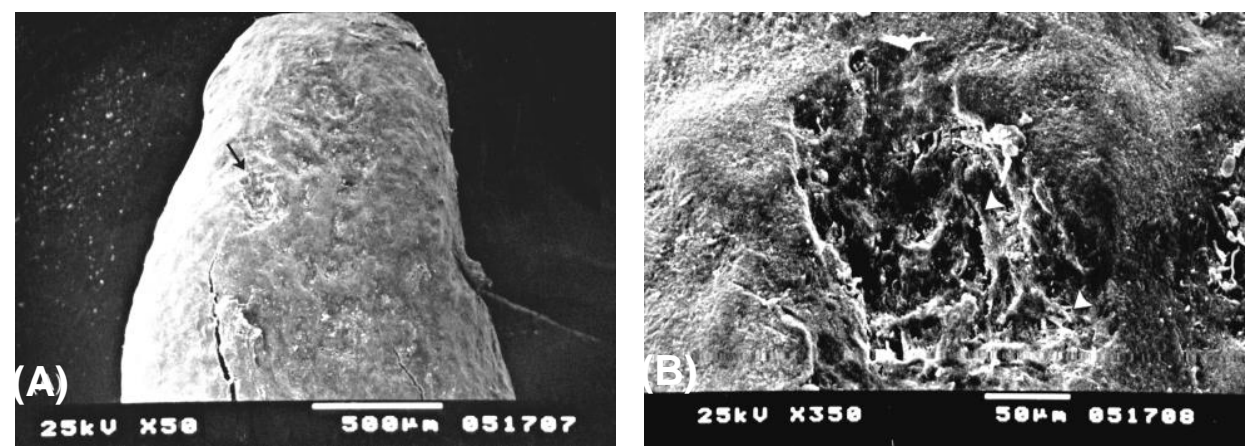

Fig.9: SEM showing: (A) partial repair (arrow) after 4 weeks retention period (B) irregular distribution of repair tissues at the floor of shallow resorption bay.
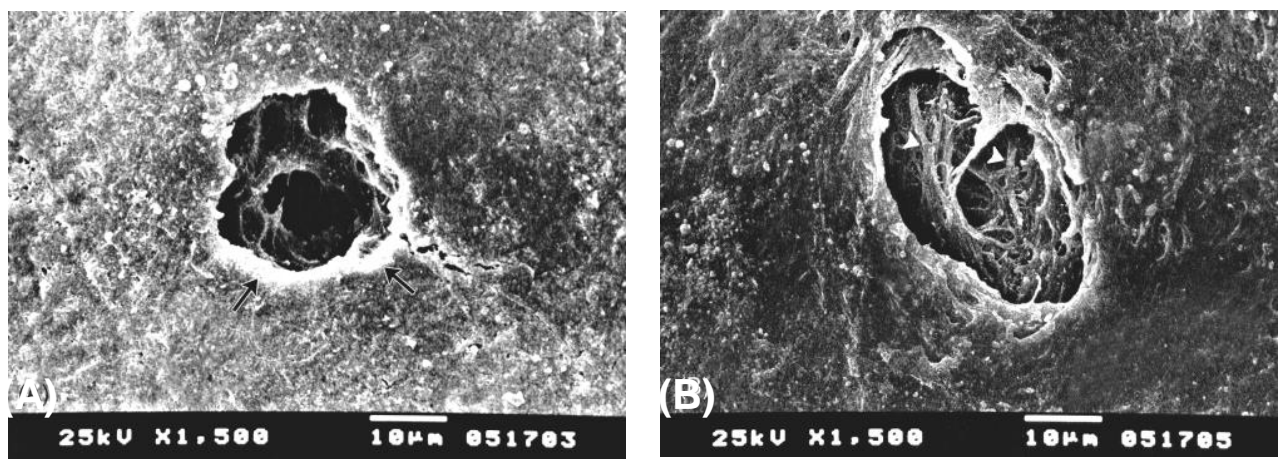

Fig.10: SEM showing (A) mineralizing cementum at the periphery of deep isolated lacunae (arrows), (B) fibers of varying diameters inserted into the periphery and floor of deep lacuna (arrow heads).
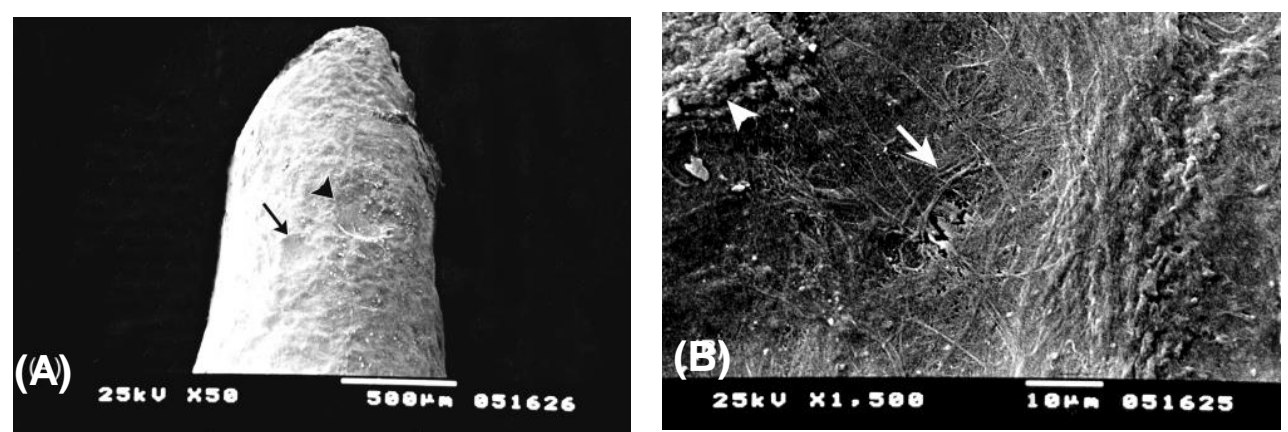

Fig.11: SEM showing (A) functional (arrow head) and anatomical repair (arrow), (B) high magnification of anatomical repair with intrinsic fiber cementum (arrow) close to old extrinsic fiber cementum (arrowhead) . 
Egyptian

Orthodontic Journal

\section{DISCUSSION}

Root cementum is a fairly independent tissue and unlike bone, is not involved in metabolic processes. Changes resemble those taking place in bone can occur, as with osteoid, cementoid tends to decrease in thickness on the compression side ${ }^{(25,26)}$. If the compression exist, root resorption progress even if it was initially protected by noncalcified tissue.

It has been documented that root resorption is frequently proceeded by hyalinization of the periodontal ligament (PDL). As a side effect of the cellular activity during removal of the hyalinization of PDL tissue, the cementoid layer of the root is left with raw, unprotected surfaces in certain areas that can readily attacked by resorptive cells. Root resorption then occurs around this cell- free tissue, starting at the border of the hyalinized zone ${ }^{(27,28)}$. Under light physiologic compressive forces, no hyalinization of the PDL occurs ${ }^{(29)}$.

The two magnitudes of force used in the present study ( $20 \& 50 \mathrm{~g})$ may be regarded as light forces from a clinical standpoint which are sufficient for tooth movement ${ }^{(12)}$ and low enough to reduce the potential of PDL hyalinization and root resorption ${ }^{(30)}$. The force $(20 \mathrm{~g})$ is below the level that often used in other clinical situations and investigations in human beings while the force $(50 \mathrm{~g})$ is considered close to ideal ${ }^{(8,31,32)}$.

The experimental design of the present work induced active tooth movement for 4 weeks for detection of root resorption and retention period for 8 weetks only thus the experimental period was not more 12 weeks for ethical reason.

The study utilized SEM in order to record the surface area as well as the depth of root resorption defects. During specimen preparation, the organic part was dissolved, allowing alteration of the mineral component of the root surface and the "foot prints" of cells on the mineralizes tissue to be observed.

The observations of the present study showed that root resorption might occur even after application of a force $20 \mathrm{~g}$ and with a force $50 \mathrm{~g}$. This is because root resorption might be preceded by partial occlusion of blood vessels ${ }^{(29)}$ or semihyalinized area which considered a preliminary stage to full hyalinization. ${ }^{(33)}$

With the application of the force 20g. region 12 was the most affected region (which is considered an area of combined compression and tension) followed by region 11 which is an areas of compression. This may be due to the fact that PDL at the middle root third is generally narrower than at the cervical and the apical thirds ${ }^{(34)}$, beside that the cervical root third is covered by 
extrinsic fiber cementum into which many collagen bundles are inserted. This condition might prevent over compression of the root surface, thus avoiding major resorptive consequences at this root level ${ }^{(35)}$.This result was in agreement with that obtained by Jimeneg and Arana ${ }^{(36)}$ who used a comparable amount of force $25 \mathrm{~g}$. buccally and $25 \mathrm{~g}$. lingnally for rotation of lower premolar. On the other hand, Acar et $\mathrm{al}^{(37)}$ found that resorption cavities were observed in the apical, middle and cervical thirds in the buccal surface and tended to be widen and extended in the middle and cervical region compared with the apical area. This may be attributed to using $100 \mathrm{~g}$ of force delivered by elastics warned 24 and 12 hours/day to deliver continuous and discontinuous force. The conflict between their results and ours could be referred to different type of tooth movement as well as the magnitude of force that varies greatly from the present study. With application of $50 \mathrm{~g}$ Of force, the distribution of resorption lacunae differers from that of group I, Region 11 showed the highest frequency followed by regions $12 \& 23$.

Although root resorption has been widely documented on the compressive side $^{(19,21,38,39)}$, the present study revealed resorption lacunae on the tention sides. This is supported by other authors reported resorption on the tension side, in animals and humans ${ }^{(29,40-42)}$. With an increase in stress, the metabolic changes observed in the compression side did not differ from those in the tension side, and the cellular changes were similar ${ }^{(43)}$, the underlying mechanism is still unknown.

Owman \& $\mathrm{Kurol}^{(44,45)}$ reported that root resorption was not sensitive to force magnitude. Moreover Stenvik and $\mathrm{Mjor}^{(46)}$ found that an increased force caused a decrease in the frequency of root resorption when premolars were intruded with $35 \mathrm{~g}$. Of force if compared with $250 \mathrm{~g}$ of force. They attributed this phenomenon to idiopathic variation, however they cautioned that the results should not mislead clinicians into using heavy force.

The technique used in their study (selective serial histological sections) might not be accurate enough, and many resorption craters might have been missed. Also, selection criteria for the premolars were not strict, and external factors that might predispose to root resorption were not excluded.

On the contrary, the premolars in our study were carefully selected to exclude any external or systemic predisposition to resorption, and the examination of roots using SEM allowed a more accurate evaluation of root resorption with 3-D analysis and enhanced visual and perspective assessment of the craters surfaces ${ }^{(20,21,38)}$. 
The pattern of resorption of group I appeared as superficial removal of the root cementum with no dentin involvement in the form of wide shallow resorption bays and small isolated lacuna, while that of group II appeared as deep resorption areas that may reach the dentin with minimum amount of small isolated lacunae. Our results coincided with King and Fischlschweiger ${ }^{(10)}$ who reported that light force produces insignificant root resorption, whereas intermediate or heavy forces resulted in deep crater formation. This result agreed with earlier findings in animals and humans ${ }^{(47-49)}$.

The small isolated lacunae of group I seems to be the effect of single cell or even a "bite" corresponding to one ruffled border zone, while the wide shallow lacunae could be a result of amoeboid movement of that cell that are not capable of producing deep resorption defects. The increased force of group II was suggested to induce the differentiation of another cell type with different resorptive potential. Moreover the number of small isolated lacunae was diminished in group II as these defects may fuse with wide resorption bays or deep lacunae. The force used in group II resulted in deep resorption lacunae with undermining edges indicating the resistance of healthy cemntum to resorption ${ }^{(24)}$.

Concerning the repair process, our results revealed that early repair with varying degrees of extension was frequently registered after 4 weeks of force discontinuation. The progress of healing showed almost the same frequency in all parts of the root, since the tooth was kept in a steady position without interference from relapse and occlusal forces, which allowed even healing process.

Although the time for healing seems to be short in the present study considering earlier reports dealing with retention periods of 16 weeks and 8 weeks of relapse in animal ${ }^{(17,50)}$ or 53 weeks in human, ${ }^{(16,51)}$ it was found that the amount of repair increased with time. The partial repair which observed after 4 weeks, lining the resorption cavities became functionally repairing the lacunae or anatomically restoring the original root contour.

These findings are in agreement with earlier investigation by Owman \& $\mathrm{Kurol}^{(52)}$, they reported that the average number of resorption lacunae showing repair increased three folds from $28 \%$ after 1 week to $75 \%$ after 8 weeks assuming that, with time, all the open lacunae would be repaired.

Morphologically the repair process of shallow lacunae was observed beginning at the bottom of the lacunae after 4 weeks of retention and gradually cover the lacunae with reparative cementum after 8 weeks of retention. On the other hand the repair of deeper lacunae start at the periphery and extended over 
the outer surface with fibers crossing the lacunae. These results coincided with that of previous authors described the healing process as beginning from the periphery ${ }^{(19)}$, the bottom ${ }^{(53)}$, or in all directions ${ }^{(54)}$ two weeks after force removal. Thus it would be expected that with higher force and deeper lacunae, the repair process takes more time to fill the resorbed lacunea, and the collagen fibers need more time to be oriented in bundle that restore the outline of the root surface.

Our results revealed also that the healing process started early during the period of active tooth movement as evidenced by areas of earlier repair in deep resorption lacune of group II. This is in concomitant with the results of Maria ${ }^{(24)}$ who suggests that deep crater formation is not a continuous process that is interrupted by deposition of cementum.

\section{Conclusion:}

1. Root resorption should be considered as unavoidable side effect during orthodontic treatment, as minimal root resorption can occur even with low force magnitude.

2. The force $20 \mathrm{~g}$. is considered optimum to produce orthodontic tooth movement without overloading of the PDL tissues, while the force $50 \mathrm{~g}$. is still rather high.

3. Root resorption is very sensitive to force magnitude, as detected by different patterns and extensions of resorption lacunae recorded with the two magnitudes of force used.

4. Repair process starts during active tooth movement and the healing potential increases greatly in the retention periods.

5. The pattern of healing varies according to the different types of resorption lacunae which depend on the magnitude of force.

\section{Recommendations:}

1- Orthodontists should apply force as light as possible, and regularly check the magnitude of force during treatment.

2- Healing time must be long enough to avoid the presence of unhealed resorption areas, as periods of rest favorably affect cell proliferation, and allow the resorption cavities to be repaired with secondary cementum.

3- Cautions must be exercised in treating patients with "high risk" so treatment can either be stopped or modified in consultation with the patient or parent. 
Egyptian

Orthodontic Journal

\section{REFERENCES}

1. Brezniak N, Wasserstein A.: Orthodontically induced inflammatory root resorption. Part I: The basic science aspects. Angle. Orthod. 2002; 72: 175-179.

2. McNab S, Battistutta D, Taverne A Symons AL: External apical root resorption following orthodontic treatment. Angle Orthod. 2000; 70: 227-232.

3. Breznial CN, Wassertein A. Root resorption after orthodontic Treatment: part 2. Literature review. Am. J. Orthod. Dentofacial Orthop. 1993; 103: 138-146.

4. Beck BW, Harris E. Apical root resorption in orthodontically treated subjects analysis of edgewise and light wire mechanics Am. J. Orthod Dentofacial Orthop. 1994; 105: 350-361.

5. Brezniak N, Wasserstein A. Orthodontically induced imflammatory root resorption. Part II: the clinical aspects. Angle Orthod. 2002; 72:180-184.

6. Artun J, Smale I, Behbehani F. Doppel D, Van't Hof M, Kwjpers Jagtman AM. Apical root resorption. Six and 12 months ofter initiation of fixed orthodontic appliance therapy. Angle orthod. 2005; 75: 919-926.

7. Nishioka M, Ioi $\mathrm{H}$, Nakata S, Nakasima A, Counts A. Root resorption and immune system factors in the Japanese. Angle. Orthod. 2006; 76: 103-108.

8. Schwarz AM. Tissue changes incident to orthodontic tooth movement. International Journal of orthod. 1982, 18: 331-352.

9. Steigman S, Michaeli Y. E xperimental intrusion of rat incisors with continuous loads of varying magnitude. Am. J. orthod. 1981, 80: 429- 436.

10. King GJ, Fischlschweiger W.. The effect of force magnitude on bone resorptive activity and cemental cratering in orthodontic tooth movement. J: Dent. Res. 1982, 6: 775-779.

11. Owman- Mol L P, Kurol J, Lundgren D. The effects of a four- fold increase root resorptions An Intra- individual study in adolescents. Eur. J. Orthod., 1996; 18: 287-294.

12. Iwasaki LR, Haack JE, Nickel JC, Mortan J.: Human tooth movement in response to continuous stress of Low magnitude. Am. J. Orthod. Dentofacial. Orthop. 2000, 117: 175- 183.

13. Vardimon AD, Graber TD, Voss LR, Lenke J.: Determinants controlling iatrogenic external root resorptions and repair during and after palatal expansion. Angle Orthod. 1991, 61: 113-122.

14. Henry JL, Weinmann JP. The pattern of resorption and repair of human cementum. Am. Dent. Assoc. 1951, 42: 270-289. 
15. Barber AF, Sims MR. Rapid maxillary expansion and external root resorptions in man: A Scanning electron microscopic study. Am J Orthod. 1981, 79: 630-652.

16. Langford SR, Sims MR: Root surface resorption, repair and periodontal attachment following rapid maxillary expansion in man. Am J Orthod. 1982; 81: 108-115.

17. Vardimon $\mathrm{AD}$, Graber TM, Pitaru S.: Rapid process of external root resorption subsequent to palatal expansion treatment. Am J Orthod Dentofac Orthop. 1993; 103: 120-130.

18. Owman- Moll. P. Kurol J, Lundgren D.: Repair of orthodontically induced root resorption in adolescents. Angle Orthod. 1995; 65: 403-410.

19. Rygh P.: Orthodontic root resorptions studied by electron microscopy. Angle Orthod: 1977, 47: 1-16.

20. Reitan K. Biomechanical principles and reactions In: Graber TU, Swain BF, editors. Orthodontics. Current Principles and Techniques, PP. 101-192, St. Louis: Mosby, 1985.

21. Reitan R: Initial behavior during apical resorption. Angle Orthod. 1974; 44: 68-82.

22. Stenvik A, Mjor I.: Pulp and dentine reactions to experimental tooth intrusion. A histologic study of the initial changes. Am. J. Orhtod. 1970, 57: 370-385.

23. Kurol J, Owman- Moll $\mathrm{P}$, Lundgren $\mathrm{D}$. Time related root resorptions after application of a controlled continous force. Am J. Orthod. Dentofacial. Orthop. 1996, 110: 303-310.

24. Maria M., Ole Ch. A, Nils J.S, Pongsri B. and Knut A.S. Early root alteration after orthodontic force application studied by light and scanning electron microscopy. Eur. J. of Orthod. 2004; 26:119-128.

25. Thilander B, Rygh P, Reitan R. Tissue reactions in orthodontics. In: Graber TM. Vanarsdall RL, editors. Orthodontics current principles and techniques. $3^{\text {rd }}$ st. louis. Mosby; 2000 P. 117-92.

26. Polson, caton J, Polson AP. Nyman S Novak J, Reed B. Periodontal response after tooth movement into intra-bony defects. J. period. 1984; 5: 197-202.

27. Kvam. E. A study of the cell free zone following experimental tooth movement in the rat. Trans. Eur. Orthod. Soc. 1969, 45: 419-340.

28. Brudvik $P$, Rygh $P$. The initial phase of orthodontic root resorption incidence to local compression of the periodontal ligament. Eur. J. orthod. 1993; 15: 249-63. 
29. Chan E. Darendelicer MA. Physical properties of root cementum: Part 7. Extent of root resorphion under areas of compression and tension. Am J. erthod. Dentofacial Ortheped. 2006; 129: 504-10.

30. Bench RW, Hilgers JJ. Gugino CF. Bioprogressive therapy, part 6. J.C.O. 1978; 12: 123-139.

31. Lee B. Relationship between tooth movement rate and estimated pressure applied. J. Dent Res. 1965; 44: 1053.

32. Storey E. The nature of tooth movement. Am- J. Orthod. 1973; 63: 293- 314.

33. Kurol J., Owman- Moll. P. Hyalinization and root resorption during early orthodontic tooth movement in adolescents. Angl Orthod. 1998; 68: 161- 166.

34. Schroeder HE. Oral structure biology. Stuttgart; Georg thieme varlag; 1991.

35. Ten cate AR. Deporter D, freeman E. The role of fibroblasts in the remodeling of periodontal ligament during physiologic tooth movement. Am. J. Orthod. 1976; 69: $155-68$.

36. Jimenez- Pellegrin $C$ and Arana- Chavez VE. Root resorption in human mandibular first premolars after rotation as detected by scanning electron microscopy. Am- J. Orthod. Dentofacial. Orthop. 2004; 126-85.

37. Acar A, Canycirek U, Kocaaga M, Ervendi N: Continuous VS. Discontinues force application and root resorption. Angle. Orthod. 1999; 69: 159:159-169.

38. Reitan K. Effects of force magnitude and duration of tooth movement on different alveolar bone types. Angl. Orthod. 1964; 34: 244-55.

39. Gaude El. Tissue changes in the monkey following root torque with Begg technique. Am- J. Orhod. 1970; 58: 164-78.

40. Williams S. A histomorphometric study of orthodontically induced root resorption. Eur. J. orthod. 1984; 6: 35-47.

41. Srivicharnkul P., Kharbanda P, Swain MV. Petocz P, Darendeliler MA. Physical properties of root cementum: Par 3. Hardness and elastic modulus after application of light and heavy forces. Am- J. orthod Dentofaeial Orthop. 2005; 127: 168- 176.

42. Chan E, Darendeliler MA. Physical properties of root cementum; Part 5. Volumetric analysis of root resorption craters after application of light and heavy orthodontic forces. Am- J Orthod. Dentofacial Orthop. 2005; 127: 186-195.

43. Baumrind $\mathrm{S}$. A reconsideration of the propriety of the pressue- tension hypothesis. Am- J. Orthod. 1969; 55: 12-22. 
44. Owman- Moll P,Kurol J, Lundgren D. Effects of a doubled orthodontic force magnitude on tooth movement and root resorptions: an inter individual study in adolescents. Eur. J. orthod. 1996; 18: 141-150.

45. Owman- Moll P. Kurol J. Lundgren D. The effect of a four-fold increased orthodontic force magnitude on tooth movement and root resorptions. An interindividual study in adolescents. Eur J. Orthod. 1996; 18: 287-294.

46. Stenvik A, Mjor IA. Pulp and dentine reactions to experimental tooth intrusion- a histologic study of the initial changes. Am- J. Orthod. 1970; 57: 370- 385.

47. Kvam E- SEM of human premolars following experimental tooth movement. Trans Eur. Orthod. Soc. 1972:1-11.

48. Dellinger El. Ahistologic and cephalometric inrestigation of premolar intrusion in the Macaca speciosa monkey Am- J. Othod 1967; 3: 325- 355.

49. Harry MR. Sims MR. Root resorption in biscupid intrusion: a scanning electromicroscopic study. Angl. Orthod. 1982; 52: 235-258.

50. Vardimon AD, Graber TD, Voss LR, Lenke J. Determinants controlling iatrogenie external root resorptions and repair during and after palatal expansion. Angl. Orthod, 1991; 61: 113- 122.

51. Langford SR, Sims M. Root surface resorption, repair and periodontal attachment following rapid maxillary expansion in man. Am- J. Orthod. 1982; 81: 108- 115.

52. Owman- Moll P, Kurol J. Root resorption pattern during orthodontic tooth movement in adolescents. In Davidovitch Z, Mah. T, eds. Biological Mechanisms o tooth Eruption, Rosorption and Replacement by Implants. Boston, Mass: Harvard Society for the Advancement of orthodontics. 1998; 415-414.

53. Hellsing E, Hammarstrom L. The hyaline zone and associated root surface changes in experimental orthodontics in rats. Light and scanning electron microscope study. Eur. J. Orhod. 1996; 18: 11-18.

54. Kurol J. Ranke P. Lundgren D. Owman Moll. P. Force magnitude applied by orthodontists. An inter and intraindividual study. Eur. J. Orhtod 1996; 18: 69-75. 